\title{
A NEW OSCILLATORY CRITERION FOR THE GENERALIZED HILL'S EQUATION
}

\author{
G. A. Grigorian
}

Abstract. In this note we use an oscillatory theorem for the second order linear ordinary differential equation in order to establish an oscillatory criterion for the generalized Hill's equation. We formulate a hypothesis about representation of the sum of periodic functions with rational dependent periods by a sum of periodic functions with rational independent periods.

Mathematics subject classification (2010): 34C10.

Keywords and phrases: oscillation, generalized Hill's equation, periodic functions, rational independence of periods, generalized Mathieu equation.

\section{REFERENCES}

[1] C. A. Swanson, Comparison and oscillation theory of linear differential equations. Academic press, New York and London, 1968.

[2] Q. Kong, M. Pasic, Second Order Differential Equations: Some Significant Results Due to James S. W. Wong Differ. Equ. Appl. 6, 1 (2014) 99-163.

[3] I. V. Kamenev, On oscillation criterion for the second order linear differential equations, Matematicheskie zametki 23, 2 (1978), 249-251.

[4] J. YAN, Oscillation theorems for second order linear differential equations with damping, Proc. Amer. Math. Soc. 98, 2 (1986), 276-282.

[5] W-L. LIU AND H-J. LI, Oscillation criteria for second order linear differential equations with damping, J. Appl. Anal. 2, 1 (1986), 105-118.

[6] M. K. KWONG, Integral criteria for second-order linear oscillation, Electronic journal of qualitative theory of differential equations, 2006, 10, 1-28. http//www.math.u-szeged.hu/ejqtde/

[7] Q. Kong, Interval Criteria for Oscillation of Second-Order Linear Ordinary Differential Equations, J. Math. Anal. Appl. 229 (1999), 258-270.

[8] O Dosly, E. Jansova, AND J. Kolas, Eighty fift anniversary of birthday and scientific legacy of professor Milos Rab, Archivum Mathematicum (Brno) 50 (2014), 1-19.

[9] J. DenG, Oscillation criteria for second order linear differential equations, J. Math. Anal. Appl. 271 (2002), 283-287.

[10] A. Elbert, Oscillation/Nonoscillation Criteria for Linear Second Order Differential Equations, J. Math. Anal. Appl. 226 (1998), 207-219.

[11] H. KH. AbDullah, A note on the oscillation of second order differential equations, Czechoslovak Mathematical Journal 54 (2004), 949-954.

[12] G. A. GRIGORIAN, On one oscillatory criterion for the second order linear ordinary differential equations, Opuscula Math. 36, 5 (2016), 589-601. http://dx.doi.org/10.7494/OpMath.2016.36.5.589

[13] G. W. HiLL, On the part of the motion of the Lunar Perigee which is a function of the mean motions of the Sun and Moon, Acta. Math. 8 (1886) 1-36.

[14] N. W. McLachlan, Theory and Application of Mathieu Functions, Oxford: Claredon Press, 1947.

[15] M. K. KWONG AND J. S. W. Wong, Oscillation and nonoscillation of Hill's equation with periodic damping, J. Math. Anal. Appl. 288 (2003), 15-19.

[16] L. Kuipers, H. Niederreiter, Uniform Distribution of Sequences, John Wiley \& Sons, N. Y. London - Sidney - Toronto, 1974 (Russian translation). 
[17] Ph. Hartman, Ordinary differential equations, Second edition, The John Hopkins University, Baltimore, Merilend, 1982. 